\title{
Políticas de leitura, práticas de leitura e formação de professores
}

\author{
Max Butlen ${ }^{1}$
}

\section{Resumo}

Este artigo trabalha com duas hipóteses. A primeira é a de que a compreensão das desigualdades nas práticas e competências de leitura dos alunos do ensino fundamental é esclarecida por uma análise crítica das políticas de leitura. A segunda hipótese postula que a melhora do desempenho supõe, de um lado, levar em conta as dificuldades e práticas de leitura e cultura reais desses jovens ; de outro lado, uma revisão sensível da formação dos professores.

Palavras-chave: Políticas de Leitura. Práticas de leitura. Formação de professores.

1 Université de Cergy-Pontoise, ESPE de l'académie de Versailles, Ágora. 


\title{
Reanding policies reandin practices and teachers praining
}

\begin{abstract}
Abstrat
This paper works with two hypothesis: the first one is that the understanding of the inequalities in practice and reading skills of elementary school students is informed by a critical analysis of reading policies. The second hypothesis assumes that the performance improvement supposes, on the one hand, taking into account the difficulties and the reading and cultural practices experienced by these young people and, on the other hand, a sensitive review of teachers training.
\end{abstract}

Keywords: Reading Policies. Reading practices. Teachers praining.

\section{Análise global das políticas de leitura: políticas de oferta}

A partir do conhecimento da experiência francesa, bem como daquela de outros países, em função também das observações que podem ser feitas nesse campo da leitura e das políticas de leitura no Brasil, podemos apontar que tais políticas, em primeiro lugar, aparecem como políticas de oferta. São políticas de oferta de livros, de bibliotecas, de discursos e de ações para se incentivar a ler (BUTLEN, 2008).

Do lado da oferta de objetos de leitura, vimos, durante o século XX, um aumento constante do número de textos e de documentos a serem lidos. Totalmente ligada à expansão do número de leitores (publics potentiels de lecteurs), a multiplicação dos objetos a serem lidos resulta do desenvolvimento das tecnologias de informação e de comunicação e dos notáveis esforços de adaptação dos editores. O setor editorial aprendeu a viver na hora da concentração crescente da produção e da difusão, mas também na hora da nova gestão. Esses processos de racionalização e de profissionalização explicam a amplificação considerável da oferta de livros e de leitura; aquela se traduz, na França, em quarenta anos, pela 
triplicação do número de títulos novos editados.

A chegada e o triunfo da internet alargaram infinitamente os horizontes e as possibilidades de leitura, assim, essa política de oferta, e mesmo de "suroffre éditoriale", fica facilitada e incentivada pelo contexto econômico e pelos avanços tecnológicos. Na aérea de nosso estudo, no contexto da Europa, os editores correm novos riscos, abrem o campo da edição para o máximo de obras, ao explorarem novas formas editoriais, novas categorias literárias para uma juventude que também está regularmente redefinida; até que, hoje em dia, a literatura infantojuvenil toma como alvo não só os bebês, desde os primeiros dias de vida, não apenas as crianças, os pré-adolescentes e adolescentes, mas também os jovens de 18 a 25 anos de idade e até mesmo os jovens adultos (young adults) de 25 até 35 anos que parecem viver na continuidade da sua adolescência, sem serem pressionados a entrarem na idade adulta.

Por todas essas razões, a produção, a quantidade da escrita é sempre maior. O exemplo da literatura infanto-juvenil francês se revela significativo. A inflação da oferta editorial impressiona há 50 anos. No ano de 1958, apenas 650 títulos foram publicados nesse setor editorial. No ano de 1975, chegamos no nível de 3500 novos títulos publicados por ano; no ano de 1990, 7245; no ano de 2000, 8350; no ano de 2012, podem ser recenseados mais de 12000 títulos (6000 novidades / 6000 reedições), e isso sem levar em conta os livros didáticos.

Do lado dos espaços de leitura, o mesmo fenômeno de amplificação. Vimos multiplicarem-se as bibliotecas públicas em quase todas as cidades francesas. Vimos bibliotecas escolares serem implantadas e dirigidas por um ensino-documentalista formado em todos os estabelecimentos, da sexta série até o ensino médio. As salas de leitura proliferaram-se no ensino de primeiro grau. Apareceram bibliotecas nos hospitais, nas empresas, nas prisões, nas creches, em quase todos os lugares de sociabilidade, e até mesmo nas ruas, nas praias e nos táxis.

A partir de 1980, vimos entrar na batalha da leitura novos agentes das políticas de leitura para a juventude, novos atores; entre outros: as instituições e as administrações públicas, vários ministérios, um bom número de eleitos de vários partidos e universitários de múltiplas 
disciplinas que, antigamente, não se preocupavam com essa área, geralmente considerada como não legítima. Os discursos e as ações para se incentivar a leitura também não faltaram: muitos responsáveis e políticos nos níveis local, regional e nacional declararam-se a favor da prioridade a ser dada à leitura. Hoje em dia, não faltam eventos para se incentivar a ler, sendo mais difícil proceder à contagem das inúmeras feiras da leitura, jornadas, semanas do livro. Também vimos muitos prêmios, muitos encontros com os autores, ilustradores e contadores de histórias.

Nunca na história tantos esforços foram feitos a favor da leitura e do livro. Muito bem. Mas, quais são os resultados?

\section{Limites das políticas de oferta}

Sem dúvida nenhuma, a oferta melhorou de maneira espetacular: o mapa das bibliotecas cresceu; o número de cidadãos inscritos nas bibliotecas e dos usuários das mesmas aumentou. Na França, as bibliotecas se tornaram o espaço cultural mais usado e, frequentemente, o mais animado. Em inúmeros municípios, aconteceram feiras do livro com forte sociabilidade entre os leitores. A economia do livro permanece nos primeiros lugares nas indústrias culturais, e o analfabetismo clássico desapareceu faz muito tempo.

Então, têm-se resultados realmente apreciáveis do ponto de vista da melhoria da oferta de leitura. E tudo isso aconteceu também com níveis variáveis em muitos outros países do mundo, entre eles, o Brasil. Claro que as políticas de oferta eram indispensáveis, e precisa-se ainda acrescentar mais esforço. Quantitativamente, esses resultados valem à pena, são honrosos, mas, se olharmos de perto o lado da recepção, essas políticas encontram limites.

O número de leitores e as competências dos mesmos, a partir de determinado momento, pararam de aumentar automaticamente. Como exemplo, tem-se o número de inscritos e de usuários das bibliotecas, que também não cresceu muito mais, após forte melhora. Entre 1973 e 2008, o número de jovens de 15 anos que tinham lido vinte livros ou mais 
durante o ano caiu de $28 \%$ para $16 \%$. O número de leitores acima de 15 anos também caiu de $24 \%$, em 1988, para $17 \%$, em $2008^{2}$. Globalmente, o número dos grandes leitores de livros caiu de um ano para o outro; e 53\% dos franceses declararam ler pouco ou mesmo não ler. A partir de 1980, descobrimos a existência de um "illettrisme", ou seja, de um analfabetismo funcional, e ainda hoje em dia esse problema não foi resolvido.

Talvez, ainda mais preocupante é o fato de observarmos grandes dificuldades em relação a muitos públicos potenciais.

\section{Como explicar esses limites? Resultados de pesquisa}

Por que esses aspectos decepcionantes? Uma hipótese é a de que houve uma ligação insuficiente entre os três elementos-chave das políticas de leitura, ou seja, os objetos a serem lidos, os espaços de leitura e o sujeito leitor. Chegamos a essa conclusão a partir de uma pesquisa explicativa complementar que fizemos tendo por base os resultados do PISA $^{3}$, os quais vamos apresentar resumidamente.

Para começar, verificamos que o enriquecimento da oferta dos objetos a serem lidos parece ser elemento indispensável para alargar os horizontes de leitura. Seria um absurdo esquecer tal necessidade, como mostram bem os resultados do PISA desde 2000, e também como confirmou nossa pesquisa explicativa. Neste trabalho, nossa meta era a de melhor entender a diversidade dos resultados dos jovens leitores de 15 anos de idade no PISA. A posse de livros em casa apareceu como fator determinante na formação dos leitores, uma condição fortemente favorável ao desempenho e um parâmetro claramente correlacionado às boas competências e ao saber ler dos alunos. Estatisticamente, quanto mais os alunos têm livros em casa e em seu quarto, mais obtêm proficiências elevadas na compreensão da escrita. Em nossa amostra representativa da diversidade escolar dos alunos de 15 anos: $72 \%$ dos alunos com alto nível de compreensão têm mais de 100 livros, enquanto

2 Fonte Le Monde, de 13 de outubro de 2015, citando DEPS Ministère de la Communication, Livres hebdo, IPSOS, GFK, SLF, SOFIA, SNE, SGDL.

3 Pesquisa complementar ao Programa Internacional de Avaliação de Estudantes (PISA), conduzida por uma equipe da Universidade Cergy-Pontoise, orientada por Max Butlen (2012). 
89\% dos alunos com baixo nível de entendimento declararam que têm menos de 100 livros em casa. Geralmente, os jovens com o menor rendimento têm menos de 10 livros em casa e em seu quarto. Esses dados confirmam outra pesquisa internacional, a de Kirsch et al. (2000), que consideravam que o compromisso com a leitura e o perfil do leitor estão muito relacionados à posse de livros.

Entretanto, de nosso lado, chegamos a considerar que, sem dúvida, a melhoria da oferta de livros é indispensável, revelando-se condição muito favorável e absolutamente necessária em todos os lugares, mas não é uma condição suficiente para se formar um leitor competente. A crença de muitos mediadores não foi sempre bem assim. Subestimouse um fator que se afirma determinante, a saber, a necessidade de se articular a posse de livros com o desempenho, de um lado, e, por outro, certo conhecimento das estratégias de leitura. Se não se articularem os resultados, performances e competências padecem.

Do mesmo jeito, registramos que multiplicar os espaços de leitura e as bibliotecas também é de grande importância. Mas vimos que o aumento dos usuários em vários países, a partir de um determinado patamar, continua progredindo pouco. Os jovens (não) leitores, que são os mais afastados da cultura escrita, não aproveitam bem esse avanço das políticas de leitura. Tal constatação é cruel, na medida em que são esses mesmos jovens que nós quisemos seduzir pelo desenvolvimento das bibliotecas e das políticas de oferta. Então, a melhoria da oferta não basta, tendo-se em vista que as novas propostas de leitura e as bibliotecas atraíram apenas os praticantes da cultura escrita, ou seja, os usuários de tipo tradicional, afastando, talvez, os outros.

Pudemos perceber que, com esse tipo de política de leitura, a oferta continuou do modo tradicional; as maneiras de se disponibilizar a leitura não foram reconsideradas; os destinatários da oferta não foram suficientemente levados em conta, bem como as práticas reais de leitura dos jovens e as novas práticas culturais dos "digitals natives". A oferta de livros e de leitura não contemplou a recepção pelos novos públicos que, de fato, são muito diferentes dos "herdeiros" descritos por Bourdieu e Passeron (1964); muito diferentes dos antigos alunos que tinham outra 
história cultural, preparando-os para entrarem na cultura da escrita. Realiza-se, em muitos países, uma política de difusão, a mesma que foi feita antigamente com os públicos privilegiados, sem se pensar nas condições de recepção dos novos públicos, geralmente, muito mais afastados da cultura escrita legítima por causa da massificação do sistema educativo.

Redescobrimos, assim, uma realidade sociológica clássica que foi esquecida, a saber: "A aproximação geográfica entre os leitores fracos e os livros não apaga a distância cultural", o que foi muito bem demostrado por Chamboredon (1970) e Bourdieu (1966).

Porém, a distância cultural aparece como o primeiro obstáculo à apropriação. Constata-se que a lógica clássica de oferta e de difusão, que foi regularmente usada no século $X X$, não se articula bem com a lógica de apropriação. No final das contas, essa conclusão confirma que os limites das políticas de leitura resultam de um esquecimento: muitas vezes, em muitos países, pensamos os objetos e os espaços de leitura, mas nos esquecemos, de certa forma, do sujeito leitor! O que nos leva a pensar que, para se formar o leitor contemporâneo, é indispensável se trabalhar a partir das práticas de leitura e das práticas culturais "reais" dos jovens. A nossa pesquisa mostrou que os jovens de 15 anos, apesar dos discursos de lamentação, leem, e mesmo eles são muito mais leitores do que se pensa, só que suas leituras não correspondem bem àquelas desejadas pelos mediadores e professores. $\mathrm{O}$ desenvolvimento eficiente das políticas de leitura e a construção do leitor moderno não podem se realizar contra a identidade dos sujeitos, contra a sua construção identitária. Levando-se em conta os êxitos e os limites das políticas de leitura desenvolvidas nesses últimos anos, trata-se, agora, de tentar integrar os ensinamentos dessa análise na elaboração de novas propostas e de novos projetos.

\section{Condições de eficiência dos projetos e das políticas de}




\section{formação de leitores}

Além das primeiras necessidades e orientações que destacamos a partir do estudo das políticas de leitura, lembramos que, para se formar um leitor equipado de amplas competências cognitivas e culturais, é preciso também se trabalhar em cima de dois obstáculos. Um deles diz respeito a fatores internos ao desenvolvimento da compreensão, ou seja, à aprendizagem inicial do código da escrita, à capacidade de se construir uma representação unificada e coerente dos textos, às estratégias de leitura desenvolvidas, à aptidão para a metacognição. $\mathrm{O}$ segundo obstáculo é mais ou menos externo à compreensão, mas pode entrar em correlação positiva com a mesma, em certas condições. Em nossa pesquisa, escolhemos destacar alguns fatores, por se constituírem hipótese favorável para a compreensão da formação dos leitores; entre eles, quisemos destacar o peso do meio cultural e familiar, o impacto das políticas de leitura, o gênero dos jovens, a importância do compromisso do sujeito leitor, o gosto pela leitura, o papel das sociabilidades frente à escrita.

Sob quais condições aparecem os fatores mais eficientes, sendo alguns externos ao letramento? Quando? Como? Quais são as correlações mais significativas?

Não se esquecendo do novo sujeito leitor, a minha equipe de pesquisa buscou apoiar-se sobre um conhecimento preciso do mesmo, das suas particularidades, práticas, competências e proficiências. Em relação a essa meta, para conduzir esta pesquisa dentro de nosso laboratório, o Centro de Pesquisa Textos e Francofonias da Universidade de Cergy-Pontoise, nós tínhamos uma base de trabalho interessante com as avaliações do PISA.

\section{Uma pesquisa complementar ao PISA}

Lembro que o PISA mede e compara as competências dos alunos de 15 anos, notadamente em três campos: compreensão escrita (letramento), cultura matemática e cultura científica (MEN, 2000, 2008). Em 2009, 
a compreensão escrita, como em 2000, esteve no centro da avaliação realizada em 65 países, dos quais 33 são membros da OCDE. Desse modo, pelo contato com o Ministério Francês da Educação, tivemos à nossa disposição elementos longitudinais, para fazermos comparações, e consideramos atentamente os resultados dos alunos franceses em letramento. Em 2009 e 2012, globalmente, os resultados franceses do PISA permaneceram aparentemente bastante estáveis (Ministério, DEP, 2000; 2008; 2010; 2012). Eles mantêm a França na média dos países com o mesmo nível de desenvolvimento, conforme os critérios da OCDE. Nossos bons alunos continuam a ser muito bem-sucedidos e bastante numerosos, rivalizando com os melhores do mundo. Sorte deles!

Entretanto, nossos resultados mostraram também três constatações bem preocupantes:

1- O número de alunos incluídos nos níveis de desempenho fraco cresce, enquanto que o número de alunos nos níveis de desempenho mais elevado permanece estável. Mas, sociologicamente, constatamos que as distâncias se aprofundaram, nos últimos 12 anos, entre os melhores e os mais fracos, os mais favorecidos e os menos privilegiados socialmente. Então, as desigualdades sociais fortalecem-se!

2- A pontuação média da população de meninos baixou significativamente, e eles são os mais numerosos no grupo de alunos com mais fraco desempenho na França (bem como em muitos países). As meninas estão bem à frente.

3- A taxa de não respostas dos alunos franceses, já superior à dos países da OCDE, continua a aumentar desde 2000, para atingir um nível que interrogue o estatuto dos erros em nosso sistema educativo francês.

\section{Uma investigação a partir de uma mostra de 85 alunos representativos}

Fizemos, a partir de amostra bem representativa, um estudo sobre as condições implicadas no desenvolvimento da compreensão da escrita (letramento) entre meninos e meninas de 15 anos de idade. Olhamos os resultados detalhados dos alunos para identificarmos os elementos favoráveis ao bom desempenho e em quais contextos e condições os 
elementos externos à compreensão geram benefícios claros a favor do desempenho em leitura.

Tínhamos outras questões adjacentes de pesquisa e outras metas:

- Ser leitor; gostar de ler é suficiente para ser um leitor competente, realmente suficiente. Em quais condições gostar de ler e saber ler se articulam?

- Tentamos identificar perfis de leitores, na medida em que, por hipótese, o conhecimento desses perfis permitiria adaptar, individualizar e ajustar a oferta de leitura, em função da variedade dos leitores. Os mediadores de leitura disporiam, assim, de ferramentas para se atuar melhor sobre as condições e sobre os fatores de formação eficiente. Nesses perfis, tentaríamos ver quais são os fatores que se articulam, e como se articulam ou não. Buscamos saber quais comportamentos, quais tipos de relações com os livros e a leitura poderiam estar associados ao bom ou ao mal desempenho dos jovens de 15 anos. Tal identificação tornaria possível saber como se deveria atuar para se superar as dificuldades.

Nesse quadro, nossa pesquisa foi quantitativa e qualitativa. Aplicamos, aos alunos selecionados, um questionário cognitivo clássico do tipo PISA. Em complemento ao modo de questionamento internacional PISA, medindo o grau de letramento, outro questionário, sobre o contexto da vida e da educação, sobre as práticas de leitura, permitiu-nos recolher informações sobre os fatores externos à compreensão em leitura, quer dizer: o ambiente sociocultural, a posse de livros. Atenção especial foi dada ao engajamento/compromisso em/com a leitura. Engajamento/ compromisso medido pela duração das atividades de leitura, pelo gosto declarado ou não pela prática, pela variedade dos atos de leitura, pela relação com a leitura, segundo os suportes (papel ou eletrônico), pelas sociabilidades em torno das leituras e pela frequência na biblioteca. Os dados obtidos não nos pareceram satisfatórios, pela exploração somente dos questionários clássicos do tipo PISA. Assim, completamo-los com uma entrevista de todos os alunos, relacionando-a com os seus resultados e com o questionário de contexto que os alunos haviam preenchido. Tais entrevistas tiveram como objetivo aprofundar os primeiros dados recolhidos sobre os fatores externos à compreensão e também sobre as 
estratégias e a leitura dos alunos.

\section{Resultados e principais fatores favoráveis}

(a) O peso considerável do meio familiar, do estatuto econômico e cultural dos pais. O exemplo dos pais leitores (ou não leitores), os modelos familiares evidentemente têm efeitos muito significativos sobre a qualidade e a eficiência da formação dos jovens leitores. Sendo parâmetro considerável, já é bem conhecido, mas observamos que, apesar de um nível de letramento fraco, o que pode, às vezes, compensá-lo é o forte empenho dos pais a respeito da leitura; um compromisso claro com a escolarização pode compensá-lo, quando outras condições também são reunidas.

(b) Também o efeito estabelecido parece muito grande: a composição social, a categoria socioprofissional das famílias inscritas e, inclusive, a fama de um estabelecimento têm peso considerável no desenvolvimento das competências e no desempenho dos jovens. As escolas que possuem os mais altos níveis globais de performance são as mais favorecidas. Em nossa mostra de 12 escolas, chegam à frente um liceu famoso e chiquérrimo da cidade de Versailles e outro, em uma cidade muito rica (Saint-Cloud). Chega em último lugar um liceu da periferia afastada e bem pobre (Trappes). E onde fica a equidade social? Ter-se-ia uma fatalidade?

Felizmente, entre os 12 estabelecimentos representativos da mostra, no terceiro lugar da classificação, de acordo com os resultados dos jovens, encontra-se um liceu de uma cidade bem popular (Argenteuil), isto apesar das muitas dificuldades sociais dos moradores. Por quê? Provavelmente por a Prefeitura desenvolver uma verdadeira política cultural e uma ótima política de leitura. As bibliotecas da cidade, além de um trabalho exemplar de difusão, repensam as formas da mediação, desenvolvem uma política de apropriação da cultura da escrita pela comunidade, são inovadoras. As escolas são envolvidas em projetos de qualidade em torno da cultura da escrita. A formação continuada dos professores acompanha o ritmo. 
Ao inverso, outra cidade, de classe média alta, chega aos últimos lugares na classificação. É uma cidade de grande periferia, longe de Paris, sem vida cultural, sem política de leitura, com escolas sem reais implicações da equipe pedagógica na aérea da leitura e da escrita.

Esses exemplos mostram que é possível corrigir, de certa forma, os determinismos sociais.

\section{O uso da biblioteca}

A pesquisa mostra que a presença, a frequência da biblioteca pode também ter efeitos compensadores. Nessa mesma cidade, Argenteuil, há um caso ideal típico, o caso de uma menina criada pela mãe, sozinha, uma obreira, sem biblioteca em casa, num apartamento pequeno. Acontece que essa menina obtém excelentes resultados, mesmo dentre os melhores da mostra. A entrevista revelou que ela é inscrita na biblioteca; frequenta dois clubes de leitura; possui numerosas sociabilidades, em torno dos livros e da leitura; discute, na livraria, com o livreiro; faz intercâmbio na internet com muitos leitores jovens e adultos. Isso demostra que ainda é preciso se pensar no papel-chave da frequência na biblioteca.

Entretanto, um assunto é de grande preocupação: os jovens entrevistados, geralmente, declaram-se pouco atraídos pela biblioteca. Os alunos com desempenhos baixos usam-na pouco; alguns só a utilizam para trabalhos escolares. Muitos falam de uma frequência mais rara, apesar de não terem livros em casa. E todos, quando a utilizam, o fazem mais como ciberespaço, favorecendo as sociabilidades. Constatamos, por muitos alunos, o uso menor frequentemente ligado à posse de um computador, como indica esse jovem, antigamente usuário da biblioteca:

Quando eu ia lá, eu fazia a mesma coisa que eu faço agora no computador. Agora, eu faço minhas pesquisas na internet. Eu não preciso mais da biblioteca, há um ano. Eu tenho computador há dois anos. Mesmo os mangás, eu os acho gratuitamente na internet.

A repetição frequente desse tipo de declaração nos conduz a pensarmos que se torna necessária, na sociedade da internet e da informação, uma redefinição das políticas de leitura para as bibliotecas, 
assim como a reformulação do projeto das mesmas.

\section{O papel das sociabilidades em torno dos livros}

Os alunos que possuem boas performances gostam de falar dos livros, o que raramente acontece pelo lado dos mais fracos. As falas seguintes testemunham essas posturas.

Um jovem (A1) com desempenho muito fraco declara:

Quando, às vezes, eu leio, prefiro guardar o que estou lendo para mim, porque, depois, as pessoas criticam o livro ou também o fato de ler. Acho que a leitura não dá para compartilhar; para mim, é individual.

As leituras, para muitos adolescentes, têm que ser feitas escondidas, na medida em que elas os expõem aos insultos e aos risos da garotada do liceu. Outro jovem (A2) considera-as com desprezo; tratam-se de bobos, de intelectuais os alunos que têm a audácia de se adornarem com essa prática. Para ele, ler é uma pratica distintiva, mas no sentido inverso do sentido acadêmico.

Muitos são os meninos com desempenho fraco na instituição que possuem a mesma opinião de A2. Já a postura das meninas é frequentemente diferente, mas, para muitos meninos (ainda mais aqueles menos favorecidos), o fato de ler e de declarar publicamente o gosto por tal prática pode vir a ocasionar o desligamento dos leitores do grupo social, do grupo de amigos que afixam e valorizam outras práticas culturais. Então, com esse tipo de jovens, como poderíamos desenvolver eficientemente a sociabilidade em torno dos livros, se não levarmos em conta esse tipo de posicionamento?

Inversamente, os alunos mais eficientes declaram gostar muito de falar dos livros com os outros, de trocar informações sobre a cultura da escrita e da literatura. E fazem isso com muita boa vontade, com os amigos, com a família, com os adultos leitores e, mais e mais, na internet. Eles se inscrevem perfeitamente numa tradição de sociabilidade letrada.

De fato, todos esses elementos confirmam que, para ser leitor, é preciso ter "um discurso a ser inscrito no mercado da leitura", como 
destacou Pierre Bourdieu (1986). Já Michel de Certeau (1990) notava como as artes do fazer individual, entre as quais, a leitura, inscrevem-se num quadro social. Toda essa escola francesa de sociologia e de história da leitura esforçou-se para mostrar como e quando as práticas individuais e sociais se ligam, conjugam-se contrariamente às crenças comuns que consideram a leitura como algo puramente individual (CHARTIER, 1985). Na França, os salões literários, que reuniam, desde o século XVII, a aristocracia e os escritores, tinham essa finalidade: promover coletivamente a escrita, a cultura da escrita; com certeza, valorizar os autores, mas também valorizar os leitores, afirmando a leitura como uma prática social distintiva. Essa tradição de sociabilidade oral em torno dos escritos e da literatura ampliou-se no século XVIII, o século das luzes, durante o qual os leitores e a leitura tiveram papel essencial nos desejos da mudança revolucionária de 1789. No século XIX, os Gabinetes de Leitura tinham igualmente essa função, que se prolongou até o século XX, com as emissões televisivas consagradas à leitura. Por fim, nossas bibliotecas escolares contemporâneas prolongam essa tradição oral e coletiva, renovando-a com a hora do conto, com circos, comitês e rodas de leitura, além dos debates argumentativos e interpretativos.

Cada um tem a possibilidade de fazer ouvir a sua fala sobre as leituras e os livros; assim, supõe-se criar condições para a emergência desses discursos, qualquer que seja a origem sociocultural dos públicos, qualquer que sejam as práticas culturais dos participantes. $\mathrm{O}$ que supõe, em primeiro lugar, refletir sobre o que dizem aqueles jovens que resistem ao compromisso com a leitura. Trata-se, nesse caso, de permitir que eles se (re) situem em relação aos livros e à leitura; por exemplo, de dizer o porquê de não lerem no sentido escolar; quais são os encontros com a cultura da escrita que eles aceitam e gostam, quaisquer que sejam. Trata-se de oferecer-lhes a possibilidade de viverem também experiências positivas com a cultura escrita, descobrindo oportunidades de vivenciarem momentos felizes e proveitosos com a leitura. Sintetizando, trata-se, para eles, de encontrarem razões para ler, e de saberem exatamente por que ler. 


\section{O gosto pela leitura, amar ler/saber ler: um assunto de debate}

Encontra-se, aqui, uma forte interrogação de nossa equipe de pesquisa, na medida em que os sociólogos franceses interrogaram, com dúvidas, a automaticidade da relação saber/gostar de ler (SINGLY, 1993; BAUDELOT, 1999; BUTLEN, 2012). Assim, intentamos verificar isso. Por outro lado, anglo-saxões como Guthrie e Wigfield (2000) e Kirsh et al. $(2000 ; 2003)$ pensam que o compromisso dos alunos com a leitura é elemento determinante para o domínio da cultura da escrita e do saber ler. Pode ser, mas sob quais condições? (AHR; BUTLEN, 2012).

Em nossa pesquisa, constatamos gosto moderado pela leitura para muitos jovens que ignoram o essencial prazer de ler. Verificamos também a existência de correlações positivas e mesmo dominantes entre os dois aspectos, amar ler e saber ler: geralmente, o saber ler se articula com o gosto pela leitura. Reciprocamente, os jovens leitores que gostam de ler têm frequentemente resultados melhores do que aqueles alunos que não gostam de tal prática. Aqueles que sabem ler bem, geralmente, gostam mais de ler do que aqueles que não sabem ler bem. Entretanto, essa articulação entre o amor, o gosto pela leitura e as competências dos leitores é bem mais variável, bem mais complicada do que aqui se expõe.

Em nossa amostra adicional ao PISA, 69\% dos alunos, os mais fracos, declararam não gastarem tempo lendo para o seu prazer. Entre os alunos com performances fracas, $2 / 3$ consideram não gostarem de ler principalmente numa perspectiva escolar. Mas 1/3 desses alunos com dificuldades de compreensão da escrita evidencia interesse pela leitura e, às vezes, verdadeiro amor pela leitura, mas sem benefício evidente! Nesse caso, como explicar essa falta de ligação entre os dois: o compromisso pela leitura e o saber ler? Observando-os, vimos que eles leem, às vezes, muito, inclusive de forma apaixonada, mas notamos que a leitura deles, caracterizada pela forte adesão aos textos de ficção, é acompanhada de fraco distanciamento crítico frente aos textos. Apesar de uma possível paixão, apontamos a falta de estratégias de leitura, com metacognição muito limitada. Afinal, a leitura deles parece uma leitura 
de pura adesão ao texto, com muitas emoções, mas sem a verdadeira capacidade de distanciamento crítico; o poder deles de ler se caracteriza com fortes limites.

E do lado dos mais eficientes? Em nossa mostra, a maior parte dos alunos mais competentes lê, por prazer, por mais de uma hora por dia. Observamos que $11 \%$ dos jovens mais competentes declararam tranquilamente não gostarem de ler, apesar de serem capazes de boas estratégias e de correta metacognição. A pesquisa internacional PISA mostra também que alunos com índice de prazer inferior à média podem ter altas performances cognitivas.

Concluímos então que, se as correlações positivas entre os dois aspectos forem efetivamente dominantes, se, em geral, o saber ler se articular com o gosto pela leitura, não haverá mais automaticidade e reciprocidade evidentes entre o gostar de ler e o saber ler, bem como não haverá automaticidade absoluta entre o compromisso com a leitura, a paixão de ler e o alto nível de letramento. O prazer de ler e o compromisso com a leitura são condições necessárias, mas não suficientes para se dispor do saber e do poder dos leitores. A dupla gostar de ler/saber ler, muito tempo considerada como a dupla vencedora na formação de leitores, parece, no final das contas, deixar o primeiro lugar para outra dupla, a qual tentamos revelar.

\section{Dois últimos parâmetros aparecerem como chaves, ainda mais quando se combinam}

O primeiro parâmetro diz respeito às estratégias de leitura. Uma estratégia de leitura é um modo ou um conjunto de modos que o leitor sabe mobilizar conscientemente para chegar a uma boa compreensão do texto. O leitor pode adaptar sua maneira de ler, por exemplo, à velocidade de leitura, à natureza do texto a ser lido, e sabe se adaptar às dificuldades encontradas para ultrapassá-las. Por exemplo, ele sabe como fazer, se não entender o sentido da escrita; sabe resumir, voltar para trás, identificar as palavras-chave, as ideias principais, verificar as representações primeiras e as antecipações iniciais que ele fez. Esse 
leitor sabe como estabelecer relações entre o conteúdo do texto e os seus conhecimentos, as suas experiências. Ele pode guardar na memória os diferentes elementos do texto para construir uma representação coerente e unificada do texto a ser lido. Ele consegue estabelecer pontes entre os diferentes elementos, as partes de um parágrafo, de uma página, de um capítulo, de um livro. Realiza inferências textuais e extratextuais; é capaz de tratar o implícito dos textos. Possui a aptidão para organizar, planejar, conduzir a leitura, além de verificar a qualidade da mesma. Sabe quais perguntas fazer a si mesmo para progredir e se apropriar da escrita (Do que fala esse texto? O que pode acontecer? Quais são as relações entre os segmentos do texto?). Se uma estratégia não se revelar eficiente, o leitor pode usar outra. Ele manifesta flexibilidade frente aos textos e afirma-se como ator e mestre da sua leitura.

No final, esses saberes cognitivos e metacognitivos fazem a diferença na qualidade das leituras. Quanto mais um leitor tiver o domínio das estratégias de leitura, mais será eficaz, mais terá o domínio do letramento. Por outro lado, essas estratégias do leitor eficaz são invisíveis para o leitor fraco. Durante séculos, não foram objetos de ensino nem de discussões. Aqui, temos uma indicação capital para melhorar a eficiência do trabalho dos mediadores e dos professores: explicitar para todos, individual e coletivamente, como desenvolver tais estratégias aparece como tarefa prioritária. Felizmente, é possível ensinar e aprender essas estratégias para favorecer o seu conhecimento e o seu domínio (GOIGOUX; SÈBE, 2000; 2008; 2011; DUFAYS, 2007; SOUZA, 2012; ROUXEL, 2013). Professores, alunos e mediadores têm que ser formados nessa meta fundamental, nessa orientação, para enriquecer radicalmente a aprendizagem. Isso não só vai enriquecer o trabalho do professor, mas também vai resultar em conteúdo novo e vai nortear as sociabilidades, as discussões nas rodas (círculos, clubes de leitura nas bibliotecas, nas famílias).

\section{A variedade das leituras}

Constatamos, em nossa pesquisa, que o segundo parâmetro-chave 
é a variedade de leitura. Ela entra numa correlação positiva com as proficiências dos leitores. Constatamos que a variedade das leituras é uma condição, fator ligado às boas performances. Uma boa articulação entre leitura informativa e leitura literária e uma prática que conjugue as duas acompanham, geralmente, os bons resultados. Do mesmo jeito, a aptidão em desenvolver práticas de leitura intensivas e extensivas sobre todos os suportes (antigos e modernos) também é indicador positivo.

Esse último parâmetro da variedade das leituras aparece ainda como indicador determinante, quando combinado com o domínio das estratégias. Isso permite sublinear que a nova dupla vencedora na formação de leitores é a dupla domínio das estratégias / variedades de leitura. Os leitores que sabem utilizar as estratégias de leitura e que também possuem leituras variadas afirmam-se como os melhores entre todos. Quanto menos um leitor as conjuga, menos ele é eficaz. A articulação entre o domínio das estratégias de leitura e a variedade das leituras permite, assim, identificar e construir perfis de leitores que correspondam e que esclareçam o nível de performances. E qual é o interesse dessa tipologia? Ela conduz os professores e os mediadores a adaptarem as ofertas, as mediações, ao perfil dos diferentes leitores. Ao invés de fazer a todos os leitores a mesma oferta de formação, quaisquer que sejam as suas competências, parece possível individualizar a oferta, em função das competências já adquiridas ou não e em relação às práticas leitoras de cada um deles. Para cada perfil, podemos nos interrogar sobre uma eficiência melhor, sobre a atuação desejável do mediador do livro e da leitura; assim, nortear as maneiras de se incentivar a leitura.

De acordo com os pesquisadores da OCDE (2011), podem-se destacar seis tipos de leitores. No primeiro conjunto, encontram-se leitores que têm domínio relativo das estratégias de leitura. Vamos chamá-los de leitores "profundos". Conjugando essa competência com a amplitude, com a importância da variedade de leituras, chegamos a constatar uma hierarquização dos resultados em relação aos jovens, que se dividem entre três subconjuntos.

No grupo 1, aparecem os jovens que têm o maior domínio das estratégias e a maior variedade de leitura. Eles leem de tudo; 
notadamente, são leitores de literatura; desenvolvem sociabilidades entre leitores; frequentam as bibliotecas e as livrarias mais do que os outros; gostam de ler e sabem ler. Formam, assim, o grupo 1 dos leitores "profundos e ecléticos". Mas, o que fazer com eles no cotidiano da sala de aula e das bibliotecas? Apenas contribuir para alimentar sua fome de ler, de continuar a se aprofundar na construção dos saberes cognitivos e metacognitivos.

No grupo 2, encontram-se alunos um pouco menos eficientes. Eles desenvolvem boas estratégias, então, são leitores "profundos", mas possuem variedade de leitura menor; por exemplo, leem menos a literatura. Podemos chamar este grupo 2 de leitores "profundos e seletivos".

No grupo 3, encontram-se ainda alunos que são "profundos" (quero dizer, possuem estratégias corretas), mas que têm uma variedade de leitura ainda menor. A leitura informativa predomina, e os seus resultados são inferiores aos resultados obtidos pelos jovens dos dois primeiros grupos. Podemos chamar o grupo 3 de leitores "profundos e exclusivos".

O que fazer então com esses jovens dos grupos 2 e 3 ? Logicamente, continuar a ensinar as estratégias, mas também procurar abrir-lhes novos caminhos para a leitura, notavelmente para a leitura da literatura, procurando textos de acordo com a identidade deles, alargando, de maneira geral, os seus horizontes de leitura.

Dentro do segundo grande conjunto (grupos 4, 5 e 6), encontram-se alunos que não dispõem de boas estratégias de leitura. De acordo com a OCDE, podemos chamá-los de leitores "superficiais". As performances deles aparecem inferiores àquelas dos jovens dos três primeiros grupos.

Nesse conjunto, os jovens do grupo 4 possuem resultados cognitivos melhores do que os dos grupos 5 e 6 . Constatamos que eles têm também variedade de leitura mais significativa do que a dos jovens dos dois últimos grupos (5 e 6), o que parece explicar a diferença de proficiência encontrada. Podemos chamar-lhes de alunos "superficiais", mas "ecléticos". O que pode fazer o professor com esses alunos? Ao pensar em tal questão, uma necessidade absoluta aparece: ensinar estratégias 
de leitura, continuando também a alimentar o seu desejo de ler.

No grupo 5, encontram-se alunos ainda menos eficazes. Além de não desenvolverem boas estratégias, têm uma variedade de leitura menor e, ainda, leem pouco a literatura. Podemos chamar o grupo 5 de "leitores superficiais e seletivos".

No grupo 6, encontram-se alunos ainda menos eficazes do que os do grupo 5: não possuem nenhuma estratégia, não gostam de ler, não sabem ler, não exploram a variedade das obras e dos suportes de leitura. Tratam-se de leitores "superficiais e exclusivos".

O que fazer com os alunos dos grupos 5 e 6? Há muitas coisas a serem feitas: fazer emergir/ensinar as estratégias, abrir o campo das leituras, favorecer as sociabilidades entres os pares, levar em conta as suas práticas culturais, as suas leituras invisíveis, a relação com o mundo e com a cultura.

\section{Consequências desta análise sobre a formação de professores}

Quais são as consequências e as incidências dessas indicações da pesquisa sobre a formação de professores? Podemos destacar e propor dois eixos de trabalhos. Em cada um, vamos apontar nossas principais sugestões para a melhoria da formação inicial e continuada.

\subsection{Primeiro eixo: rever, repensar a oferta escolar de leitura}

Nesta meta, precisa-se de:

a) aceitar a ideia de que os jovens têm práticas de leitura, leem, mesmo que essas leituras não sejam as desejadas e as esperadas pelos professores;

b) diversificar, alargar a oferta pedagógica e cultural, levando-se em conta as leituras invisíveis (PENLOUP, 2001), as práticas reais na sala e fora da sala de aula; apoiar-se mais sobre os conhecimentos, sobre as competências que eles desenvolvem nas suas leituras usuais, para amplificar tais habilidades e saberes no campo da leitura e da literatura, para abrir novos horizontes culturais, para estabelecer pontes entre a sua cultura e a cultura erudita; 
c) abrir, enriquecer a oferta de leitura para os adolescentes, colocando o sujeito leitor no centro da atuação pedagógica;

d) trabalhar mais a partir da recepção dos textos pelos alunos; promover a iniciativa, o compromisso pessoal com a leitura, a expressão de opiniões, a tomada de posições individuais;

e) revalorizar a postura de adesão aos textos literários, promovendo também o sentido de uma necessária postura de distanciamento;

f) organizar sociabilidades entre jovens leitores, apostando nos debates de recepção, de compreensão e de interpretação, bem como na confrontação das leituras, das estratégias, das maneiras de ler e de todos os saberes dos jovens.

\subsection{Segundo eixo: redefinir o ensino da leitura e da literatura; os seus desafios atuais, as suas concepções, representações, modalidades; seus objetivos e suas abordagens}

O proposto no segundo eixo supõe um conjunto de condições favoráveis:

a) aceitar e integrar coletivamente, na equipa pedagógica, a meta de se formar leitores polivalentes, capazes de lerem todos os tipos de textos, sobre todos os suportes, segundo todas as modalidades; de se formar leitores cooperativos e críticos dos textos a serem lidos, bem como das práticas de leitura;

b) compartilhar essa tarefa entre todos os professores, durante toda a escolaridade, até a universidade; compartilhar esse papel com todos os mediadores da leitura (bibliotecários, profissionais do livro e da leitura, pais, educadores etc.);

c) desenvolver uma verdadeira pedagogia da compreensão e da interpretação. Esta orientação pedagógica é possível, necessária, indispensável. Por meio dela, trabalham-se as posturas e os gestos profissionais que ajudam os alunos a tratarem o implícito, a realizarem inferências (intratextuais e extratextuais) sobre todos os tipos de textos, sobre todos os suportes, na leitura documentária e na leitura da literatura;

d) instalar saberes metacognitivos para ajudar cada aluno a planificar as suas leituras e a ultrapassar os obstáculos cognitivos e culturais;

e) buscar e formar professores aptos a adotarem posturas inovadoras, a criarem situações-problema de leitura, ao abrirem espaços de investigações na cultura da escrita, a escolherem procedimentos que favoreçam o trabalho 
individual e coletivo de compreensão e de interpretação, ao evitarem impor sua interpretação. Esse comportamento vai permitir a emergência da diversidade das recepções, da verbalização dos modos de se compreender ou de se interpretar. Ou seja, para resumir, ao recentrar o trabalho docente nos obstáculos para a compreensão, ao tornar visível aquilo que, na atividade do leitor perito, é invisível para o leitor inexperiente, permite-se a revelação do texto do sujeito leitor (LANGLADE et al., 2006; 2011);

f) apoiar-se sobre os recursos e a prática da intertextualidade - trata-se de ter gestos e atitudes profissionais que organizem o confronto das leituras, que apostem na troca de saberes, no debate, na conquista das estratégias eficientes de leitura. Desse modo, finalmente, a comunidade de leitores vai poder apreciar a validade dos sentidos possíveis, arbitrando sobre os "direitos do texto" e sobre os "direitos do leitor" (TAUVERON, 2002), ao se afastar coletivamente os delírios interpretativos pelo retorno argumentado ao texto, após releituras e reformulações.

\section{Considerações finais}

Apesar de todos os discursos que explicam que ler é entender, parece faltar, na formação do leitor, paradoxalmente, a compreensão. A consequência é a exclusão de numerosos jovens que não entram no implícito dos textos e da língua da escola. Para resolver esse problema, novos caminhos se abrem para a formação de professores, bem como para a formação de leitores. O desafio, hoje, é trilhar esses caminhos com audácia, com voluntariedade, esperando e militando para que seja possível se passar de uma política centrada nos objetos a serem lidos a uma política centrada nos leitores. Mais do que nunca, parece oportuno trabalhar mais e melhor o compromisso com a leitura, com o ensino das estratégias de leitura, pois o sucesso das políticas de leitura demandam, hoje, por mudanças em seus modos de oferta. No essencial, trata-se de considerar o conceito de mediação e de condições contemporâneas da transmissão cultural. 


\section{Referências}

AHR, S. ; BUTLEN, M. Savoir lire/aimer lire : un couple en évolution ou en voie de séparation? In: ÉLALOUF, M. L. (Dir.). Études de linguistique appliquée. Les connaissances cachées développées par la lecture et l'écriture électronique extrascolaires. Revue Èla. Etudes de linguistique appliquée, revue de didactologie des langues-cultures et de lexiculturologie, Paris, n. 166, 2012.

BAUDELOT, C.; CARTIER, M.; DEPREZ, C. Et pourtant ils lisent... Paris: Seuil, 1999.

BOURDIEU, P. L'amour de l'art. Paris: Les éditions de minuit, 1966.

BOURDIEU, P. ; PASSERON, J. C. Les Héritiers. Les étudiants et la culture. Paris: Le sens commun, 1964.

BUTLEN, M. Les politiques de lecture et leurs acteurs. Lyon: INRP, 2008.

BUTLEN, M.; AHR, S. et al. Rapport à partir d'une recherche complémentaire à PISA. À la direction de l'évaluation, de la prospective et de la performance du ministère de l'éducation. 2012.

BUTLEN, M., HOUDART-MEROT, V. (Dir.). Interprétation et transmission littéraire à l'école. Cergy-Pontoise: UCP, Encrage, 2009.

CHAMBOREDON, J. C. ; LEMAIRE. Proximité spatiale et distance sociale. Revue française de sociologie, v. 11, p. 3-33, 1970.

CHARTIER, R. (Org.). Práticas da leitura. São Paulo: Estação Liberdade, 1985.

DONNAT, O. Les pratiques culturelles des Français à l'ère numérique: enquête 2008, Ministère de la Culture et de la Xommunication. Paris : La Découverte, 2009. 
DUBOIS-MARCOIN, D.; TAUVERON, C. (Dir.). Pratiques effectives de la littérature à l'école et au collège. Repères, Lyon, n. 37, 2008.

DUFAYS, J. L. Le pluriel des réceptions effectives - Débats théoriques et enjeux didactiques. Recherches, n. 46, p. 71-90, 2007.

GOIGOUX, R.; SEBE, S. Apprendre à lire à l'école. Paris: Èditions Retz, 2011.

Nathan, 2000.

Enseigner la lecture. Apprendre à lire au cycle 2. Paris:

Lector \& lectrix, apprendre à comprendre les textes narratifs.

Paris: Èditions Retz, 2008.

GUTHRIE, J. T.; WIGFIELD, A. Engagement and motivation in reading. In: DANS KAMIL et al. (Eds.). Handbook of reading research. New York: Erlbaum, 2000. v. 3.

KAMIL, M. L. et al. (Eds.). Handbook of reading research. New York: Erlbaum, 2000. v. 3.

HARVEY, S.; Goudvis, A. Strategies that work: teaching comprehension for understanding and engagement. 2. ed. Portland, Maine: Stenhouse Publisher, 2007.

KIRSCH, I. et al. La lecture, moteur de changement. Performances et engagement d'un pays à l'autre. Résultats de PISA 2000. Paris: OCDE, 2003.

Reading for change. Performance and engagement across countries. Results of PISA 2000. Paris: OCDE, 2003.

LANGLADE, G.; ROUXEL, A. (Dir.). Le sujet lecteur, lecture subjective et enseignement de la littérature. Rennes: PUR, 2006. 
MAZAURIC, C.; FOURTANIER, M. J.; Langlade, G. Le texte du lecteur et textes de lecteurs en formation. Bruxelles: Peter Lang, 2011. (Coll. ThéoCrit.).

MINISTERE DE L'EDUCATION NATIONALE. Cadre d'évaluation de la compréhension de l'écrit pour PISA.Comparaisons internationales. Education et formations, Paris, n. 78, 2010.

MINISTERE DE LA JEUNESSE, DE L'EDUCATION, DE LA RECHERCHE. Les compétences des élèves français à l'épreuve d'une évaluation internationale. Premiers résultats de l'enquête PISA 2000. Les dossiers de la direction de la programmation et du développement, Paris, n. 137, nov. 2008.

OCDE. Résultats du PISA 2009. Paris: Èditions OCDE, 2011. v. 1-6.

PENLOUP, M. C.; REUTER, Y. (Dir.). Les pratiques extrascolaires de lecture et d'écriture des élèves. Repères, Lyon, n. 23, 2001.

ROUXEL, A.; LANGLADE, G.; REZENDE, N. L. Leitura subjetiva e ensino de literatura. São Paulo: Edição Alameda, 2012.

SINGLY, F. De. Les jeunes et la lecture. Les dossiers de Education et Formations, Paris, n. 24, 1993.

SOUZA, Renata Junqueira et al. Ler e compreender: estratégias de leitura. Campinas, SP: Mercado de Letras, 2010.

TAUVERON, C. Lire la littérature à l'école. Paris: Hatier, 2002. 